\title{
UMA PERSPECTIVA HISTÓRICA DO ENSINO DA MATEMÁTICA NO FEMININO
}

\section{A historical perspective of Mathematics in the feminine education}

Helena Castanheira Henriques ${ }^{1}$

\section{Resumo}

A idéia de mulher, subjacente ao pensamento do século XIX, encontra-se associada ao conceito de doméstica, sendo-lhe reservados os papéis de esposa e mãe. A sua atividade encontrava-se dividida pelas tarefas de dona de casa e de educadora. Estará assim na base do implemento do ensino feminino, a necessidade de valorizar o papel da mãe educadora dos futuros homens. Como a educação das raparigas tinha como finalidade o exercício da matemidade, é evidente que os conteúdos a lecionar no ensino feminino centravam-se quase exclusivamente na educação moral, e ainda na aprendizagem da leitura, da escrita, da aritmética simples, completadas com os trabalhos de agulha (coser, bordar, tricotar). Tentaremos analisar a evolução do ensino feminino, particularmente no que diz respeito à Matemática, focando a presença ou ausência desta disciplina e tentando encontrar algumas justificações para o desenvolvimento dos planos curriculares do ensino feminino.

Palavras-chave: História; Ensino; Mulher; Matemática.

Doutora em Matemática - Ramo de História e Didática da Matemática. ISCAP - Instituto Politécnico do Porto, CMUP - Centro de Matemática da Universidade do Porto - Portugal helenachenriques@sapo.pt ; mhach@iscap.ipp.pt 


\section{Abstract}

The idea of woman, subjacent to the thought of century XIX is associated to the domestic concept, being to it reserved the papers of wife and mother. Her activity met divided by the tasks of educator and house owner. It will be thus in the base of the implement of feminine education, the necessity to value the mother paper educator of the future men. As the education of girls had as purpose the exercise of the maternity, it is evident that the contents to teach in feminine education relied almost exclusively in moral education and, still, in the leaming of reading, writing, simple arithmetic, completed with the needle works. We will try to analyse the development of the feminine education, particularly in what concerns to the Mathematics, the presence or absence of this discipline and trying to find some justifications for the development of the curricular plans of feminine education

Keywords: History; Education; Woman; Mathematics.

\section{Em torno do Ensino Feminino}

Desde o século XVI, assistimos a um aceso debate sobre o lugar das mulheres. Na verdade, quase todos os discursos versam mais sobre a necessidade de fazer da mulher uma presença discreta que é necessário limitar.

Segundo Rousseau, o papel das mulheres em relação aos homens seria:

Agradar-lhes, ser-lhes útil, fazer-se amar e honrar por eles, educá-los enquanto são pequenos, cuidar deles quando adultos, aconselhá-los, consolá-los, tornar-lhes a vida agradável e doce, eis os deveres das mulheres em todos os tempos, e o que se lhes deve ensinar desde a infância (p.703).

Obviamente que esta imagem de mulher reduzida à reprodução e manutenção da espécie define a função e o papel da mulher.

A instrução da mulher surge como uma necessidade social que visava a dar-lhe mais aptidões para educar os seus filhos e não a sua própria valorização. Como a instrução das raparigas tinha como finalidade principal o apoio dos filhos, para além dos rudimentos de leitura e escrita, aprenderiam educação moral e os trabalhos de agulha (coser, bordar, tricotar).

$\mathrm{O}$ conceito de mulher, notoriamente associado ao conceito de dona de casa, mãe e educadora, é ainda predominante no século XIX e não se apagou durante o século XX.

Só em 1835 se implementou a Instrução Primária das raparigas, sendo que em dez anos depois apenas existiam 25 escolas femininas (991 masculinas) (COSTA, 1900, p.171) 
A criação do ensino técnico em 1852, pelo decreto de 30 de dezembro, não fazia qualquer menção ao sexo feminino. Por omissão, era então permitida a inscrição de raparigas. De qualquer modo, o ensino nas escolas industriais e de desenho industrial só iniciou funcionamento em 1884/85. As aulas eram mistas à excepção da Escola Marquês de Pombal (Álcantara) e Escola Afonso Domingues (Xabregas) que tinham classes só femininas.

Em 1870, D. António da Costa pretendeu criar duas Escolas Normais para o sexo feminino (Decreto 3 de agosto de 1870), mas saindo do Govemo logo de seguida, foi o Decreto revogado.

Na década de setenta do século XIX, o ensino primário complementar para o sexo feminino compreendia: Leitura e Recitação em prosa e verso; Caligrafia e exercícios de Escrita; Aritmética e Geometria elementar e suas aplicações usuais; Gramática e exercícios de Língua Portuguesa; Sistema Legal de Pesos e Medidas; Elementos de Cronologia, Geografia e História de Portugal; Desenho Linear e suas aplicações mais comuns, Moral e História Sagrada e ainda, obviamente "os deveres de mãe de família e as prendas de bordar a cores tomar medidas e tirar moldes e fazer flores e renda" (Carta de Lei de 2 de maio de 1878).

Apesar de o número de escolas primánias femininas ter aumentado 583\% entre 1854 e 1868, em 1866 havia 216 escolas femininas contra 1660 escolas masculinas. (ARAÚJO, 1996, p.168, CORVO, 1866, p.15).

A Reforma de 1884 não aludia ao ensino feminino, no entanto, é nesta data que se registram matrículas de raparigas em dois terços das escolas do país. As aulas eram mistas à excepção da Escola Marquês de Pombal (Alcântara) e da Escola Afonso Domingues (Xabregas) que tinham classes femininas. No primeiro ano, as matrículas incidem no desenho. Só em 1887/88 uma aluna freqüenta Matemática na Escola Francisco Holanda (GUIMARÃES)

Somente em 1886 Emídio Navarro regulamentará sobre o ensino profissional feminino, definindo o funcionamento da oficina de lavores femininos da Escola Marquês de Pombal.

\section{I - Evolução do Ensino Industrial na Europa do século XIX}

\begin{tabular}{|l|l|l|l|}
\hline PAÍSES & ANOS & RAPARIGAS & RAPAZES \\
\hline FRANÇA & 1872 & $34 \%$ & $27 \%$ \\
& 1901 & $20 \%$ & $15 \%$ \\
ITÁLA & 1871 & $76 \%$ & $62 \%$ \\
& 1901 & $54 \%$ & $42 \%$ \\
ESPANHA & 1877 & $81 \%$ & $63 \%$ \\
PORTUGAL & 1900 & $71 \%$ & $56 \%$ \\
& 1890 & $85,4 \%$ & $72,5 \%$ \\
\hline
\end{tabular}

Fonte: Pinto, Teresa; O Ensino Industrial Feminino Oitocentista, p. 39

Revista Diálogo Educacional, Curitiba, v. 6, n.18, p.123-133, maio./ago. 2006. 
Em 1888, alude-se pela primeira vez que o ensino se destina aos dois sexos, não devendo ser diferenciado em função do sexo (Decreto de 23 de fevereiro) e ainda neste ano Luciano de Castro criou três liceus femininos em Lisboa, Porto e Coimbra. O curso diferente do dos liceus masculinos teria quatro anos com seis disciplinas em cada um. Uma delas era a Matemática. Novamente a medida ficou no papel.

A reforma Jaime Moniz datada de 22 de dezembro de 1894 reafirma que o curso liceal era igual para todos, mas em 1897, foram suprimidos os cursos industriais para o sexo feminino, tendo sido criados, em sua substituição, o de lavores femininos. As mulheres novamente limitadas à "arte da agulha".

Um passo à frente, dois para trás.

Também podemos ver pelo quadro seguinte, que nos finais do século XIX, o número de raparigas que frequentava o ensino técnico oscilava entre os $10 \%$ e os $18 \%$.

\section{II - Taxa de frequência feminina no Ensino Técnico}

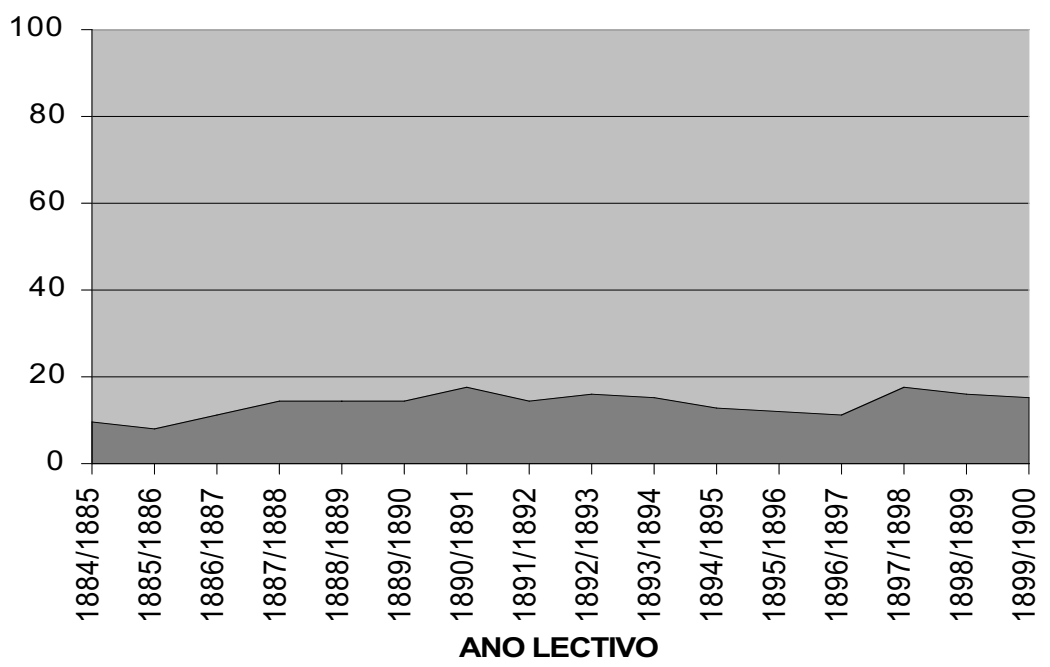

Em 1899-1900 existiam 24 liceus, freqüentados por 2848 rapazes e 59 raparigas.

A crença num ensino secundário feminino, com preparação claramente inferior ao masculino, foi uma constante na Europa oitocentista.

XIX/XX. Até então o ensino feminino assentava no ensino particular e religioso. 
Como já referimos, a criação dos liceus femininos em Portugal foi legislada em 1888 por José Luciano de Castro. Não saiu, no entanto, do papel, tendo sido suprimida em 1892. A possibilidade das raparigas concluírem os seus estudos nos liceus oficiais ficou novamente adiada, restando-lhes apenas fazerem exame como alunas externas. Obviamente que a preparação teria que ser particular, o que à partida era logo socialmente discriminatório.

Somente em 1906 se assistiu à criação do ensino liceal feminino, data marcante para o ensino feminino português, pese embora a herança pois:

a principal missão do liceu é criar mulheres instruídas e ilustradas suficientemente para poderem sem humilhação do seu próprio espírito comparecer na sociedade culta, conviver com as pessoas ilustradas, ensinar os seu filhos, fazer a escrituração da sua casa ou a do comércio dos seus, compreender os livros e a conversação dos principais idiomas da Europa, sobre a posse de prendas próprias do sexo ou lavores delicados, que ou são recursos de modesta e honrada indústria para o granjeio da vida ou recreio agradável para horas feriadas e entretimento de ócios (DECRETO de 31/01/1906)

Ainda acrescentava que para evitar a promiscuidade, agravada certamente pela introdução da Ginástica, as alunas até ao 5o ano não se podiam matricular em liceus masculinos. Sendo este o decreto criador do primeiro liceu feminino - Liceu Maria Pia - onde fariam o Curso Geral as meninas que não fossem de Lisboa?

O Curso Geral, com quatro anos, tinha sete disciplinas: Moral, Direito Moral e Religioso, Português, Francês, História e Geografia, Ciências Físiconaturais e Matemática com uma carga horária inferior ao Curso Geral masculino. No último ano, acrescentavam-se Pedagogia, Higiene e Economia Doméstica. Este liceu, contrariamente aos liceus masculinos, foi gratuito até 31/8/1912.

O Liceu Maria Pia possuía apenas o Curso Geral, pelo que as raparigas que desejassem fazer o Curso Complementar teriam que matricular-se nos liceus masculinos.

Neste liceu, a disciplina de Matemática foi leccionada pela primeira mulher portuguesa licenciada em Matemática: Domitília Carvalho, de quem falaremos mais adiante. É curioso que este liceu, por ser público, não permitia a docência feminina (só em 1926 as mulheres tiveram acesso à Função Pública), mas a forma de se contornar a lei foi que o liceu era público, mas as aulas eram privadas.

Atendendo ao grande aumento anual da população feminina dos liceus, em 1914, foi instituído junto dos liceus do Porto e Coimbra uma secção feminina para as alunas do curso geral, para que:"sejam ministrados às alunas diversos conhecimen tos que no futuro as habilitem ao perfeito desempenho dos seus deveres domésticos" (DECRETO de 17/11/1914). 
As aulas não eram públicas (as escolas sim), podendo as mães ou as pessoas do sexo feminino da família das alunas assistirem. Permitia ainda 0 mesmo decreto que nas capitais de distrito onde não existissem secções femininas, pudessem as raparigas freqüentar liceus masculinos.

A Matemática leccionada nos três anos tinha uma distribuição horária de 5, 4, 4 horas semanais, respectivamente.

No ano seguinte, considerando que a utilidade prática da educação feminina era ainda deficiente, foi criado um curso especial, anexo ao Liceu Maria Pia. Tinha como fim ministrar uma formação em matérias mais teóricas.

Estas medidas incrementaram o ensino feminino que passou de $11,2 \%$ em 1910 para 25,2\% em 1916.

Em 1918 as secções femininas dos Liceus de Porto e Coimbra tornaram-se estabelecimentos independentes, continuando a ministrar apenas o Curso Geral, ao qual se adicionou uma aula de economia doméstica com o fim de "preparar a mulher para a vida do lar e educadora de filhos e para todas as situações que não impliquem competência com o homem" (DECRETO de 11/ 11/1918).

\section{III - Distribuição horária da Matemática no Curso Geral}

\begin{tabular}{|l|c|c|c|c|l|}
\hline & \multicolumn{3}{|c|}{ 1. Seção } & \multicolumn{3}{|c|}{ 2.- Seção } \\
\hline & I & II & I & II & III \\
\hline Matemática & 5 & 4 & 3 & 3 & 3 \\
\hline
\end{tabular}

No Liceu Maria Pia de Lisboa foram criados o Curso Complementar de Letras e de Ciências. Previa a totalidade do plano de estudos dos liceus masculinos que no caso das ciências era o seguinte: 


\section{IV- Plano curricular do Curso Complementar de Ciências}

\begin{tabular}{|l|l|l|}
\hline Disciplinas & VI & VII \\
\hline Português e Literatura Portuguesa & 3 & 3 \\
Inglês & 3 & 3 \\
Geografia & 2 & 2 \\
Matemática & 4 & 4 \\
Ciências Naturais & 2 & 2 \\
Física & 3 & 3 \\
Química & 3 & 3 \\
Propedêutica filosófica & 2 & 2 \\
Ginástica & 1 & 1 \\
Desenho & 2 & 2 \\
Trabalhos práticos & 6 & 6 \\
\hline
\end{tabular}

É ainda de referir que em 1919 houve uma diminuição do número de horas de Matemática no Curso Geral, mas no Curso Complementar de Letras foi introduzida a Matemática em substituição das Ciências Físico-Químicas (DECRETO de 26/9/1919).

O Regulamento das escolas industriais informava que as escolas se destinavam a ambos os sexos (art. $2^{\circ}$ ). $O$ ensino compreendia três graus sendo leccionado no $1^{\underline{0}}$ grau: Noções de aritmética e geometria (3 horas semanais). $\mathrm{O}$ ensino feminino distinguia-se do masculino, como não podia deixar de ser, por conter noções de costura, bordados, rendas e cartonagem. No $2^{\mathrm{o}}$ grau (formação de aprendizes) com quatro anos, fazia parte do programa do $1^{0}$ e $2^{\circ}$ ano Aritmética e Geometria com 3 horas semanais (DECRETO de 19/12/1919).

\section{V - Frequência e evolução do secundário feminino}

\begin{tabular}{|l|l|l|l|}
\hline Anos & $\begin{array}{l}\text { População feminina } \\
\text { em idade escolar }\end{array}$ & Alunas dos liceus & \% \\
\hline 1910 & 586417 & 924 & 0,9 \\
1920 & 603489 & 2462 & 2,1 \\
1930 & 613202 & 2962 & 1,9 \\
\hline
\end{tabular}


liceus.

A partir 1926, as mulheres passam a poder lecionar também nesses

Já em plena Ditadura, acentuam-se novamente as linhas que marcaram todo o ensino feminino. Ficou expresso que nos cursos especificamente femininos bem como nos demais, as raparigas teriam que frequentar as disciplinas de Puericultura, Economia Doméstica e Noções Gerais de Enfermagem. Afirmava ainda que seriam regulamentados os cursos industriais nos quais seria permitido a matrícula de raparigas, devendo-se "evitar a coeducação". Essa regulamentação surgiu com o Decreto de 11 de julho desse ano. Criaramse duas escolas industriais femininas em Lisboa e no Porto, três escolas técnicas elementares femininas em Lisboa, uma em Cascais, Coimbra, Vila Nova de Gaia, Funchal, Faro e Porto. Nas escolas industriais femininas seria ministrado o ciclo preparatório e o curso profissional de formação feminina, com a especialização de modistas de vestidos, modista de roupa branca e bordadorarendeira. $\mathrm{O}$ pessoal das escolas femininas teria que ser todo do sexo feminino (LEI de 19/6/1947).

\section{A mulher na Universidade}

Até 1772, o ensino da Matemática de nível superior estava reservado essencialmente às academias militares, razão pela qual não se regista a presença feminina. A partir de 1772, com a reforma da Universidade de Coimbra, assistiu-se à criação da Faculdade de Matemática. Apesar de aparentemente não estar vedado o acesso às mulheres, na realidade as saídas profissionais destinavam-se ao sexo masculino. Os alunos que concluíssem a Faculdade de Matemática destinavam-se:

1- Ao serviço de Campanha e da Marinha.

2- Ao ensino público e particular das Ciências Matemáticas fora da Universidade.

Ora relativamente à $1 .^{\text {a }}$ saída é evidente que não se aplicava à mulher

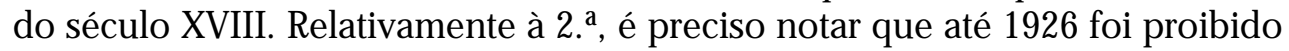
às mulheres serem docentes nos liceus masculinos, pois estava-lhes vedado 0 acesso à Função Pública.

Somente mais de um século decorrido, entrou a primeira mulher na Universidade de Coimbra (única até 1896) - Domitília Hormizinda Miranda de Carvalho (1871-1966), que viria a tornar-se na primeira mulher formada em Matemática $^{2}$ e na primeira docente de matemática. Já havia matrículas desde 1880 na Academia Politécnica, mas sem frequência de Matemática.

2 Em 1895 formou-se em Filosofia e em 1905 em Medicina. 
Quando em 1906 surgiu o primeiro liceu feminino (Liceu de Maria Pia), Domitilia tomou posse como reitora, cargo que ocupou até 1912 e aí exerceu também o cargo de professora efectiva de Matemática. Note-se ainda que durante duas legislaturas - 1934/37 e 1938/1941 - foi uma das três primeiras deputadas portuguesas à Assembléia Nacional.

Rita Morais Sarmento foi a primeira engenheira civil de obras públicas e de minas, tendo obtido carta de capacidade em 30 de julho de 1896. Depois dela, só em 1934-35 se matriculou outra mulher em Engenharia - Isabel Gago - que também foi a primeira docente feminina do Instituto Superior Técnico (mais uma em 1939/ 40; 4 em 1942/43; 8 em 1943/44).

Em 1910, apenas vinte e três mulheres estavam matriculadas em instituições de ensino superior. A Universidade de Coimbra, única existente, era frequentada por apenas 5 alunas (1262 rapazes), pelo que as restantes freqüentavam as escolas politécnicas ou institutos.

Só quinze anos após a criação da Universidade (1911) é que foi permitido às mulheres o trabalho na Função Pública, pelo que só a partir daí tiveram acesso à docência no ensino superior, pese embora na posição mais baixa.

Em 1943/1944 a Faculdade de Ciências tem 825 alunos, 185 dos quais são raparigas. terreno.

A partir de meados do século XX, percentagem de mulheres foi ganhando

Entre 1997 e 2003 a percentagem de mulheres no ensino superior aumentou $12 \%$ e atualmente sete em cada dez diplomados são mulheres, só estando em minoria nas engenharias.

Pela consulta da tabela seguinte, podemos constatar que no início dos anos sessenta, a percentagem das mulheres docentes na Universidade rondava os 10\%.

\section{VI - Percentagem de Mulheres Docentes Universitárias}

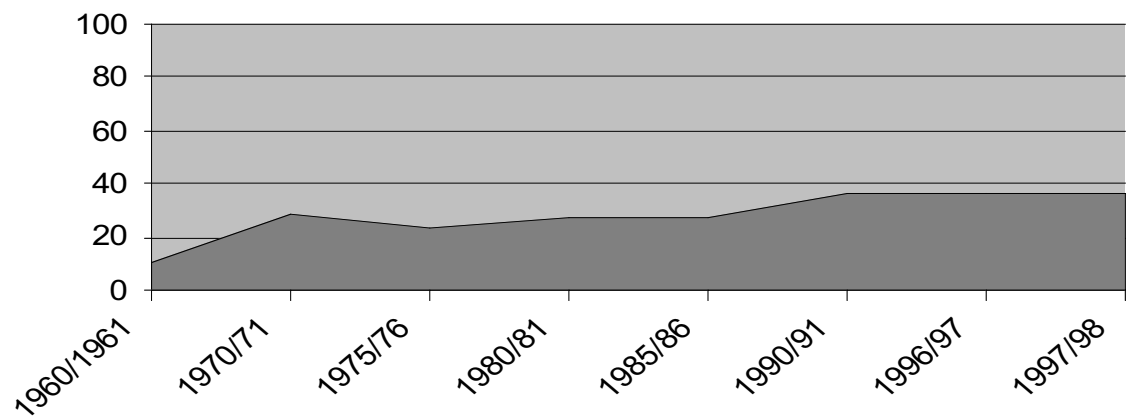


Ainda hoje e apesar do número de mulheres docentes ser próximo do dos homens, o acesso ao topo da carreira é substancialmente mais difícil.

\section{Conclusão}

$\mathrm{O}$ percurso do ensino feminino foi algo atribulado, porque assentou sempre num conceito de mulher destinada a servir o seu marido, exercer a maternidade e educar os filhos. Às filhas, bastava ensinar as tarefas domésticas e incutir-lhe a subserviência a seu pai e ao futuro marido, isto é, aos homens dos quais dependeria. Ainda hoje ouvimos, naquele a que chamamos o "Portugal profundo", mulheres referirem-se ao seu marido como o "Meu Senhor". Este conceito ainda não foi totalmente abandonado. Talvez por isso seja ainda difícil elas atingirem os cargos mais altos. Isto é bem visível, por exemplo, no Parlamento português, para o qual se fala na instituição de quotas para alargar a percentagem feminina. Demoraram alguns anos, mas hoje a percentagem de mulheres que frequenta o Ensino Secundário e Superior ultrapassou a dos homens e a igualdade de oportunidades começa a concretizar-se.

\section{Referências}

ALBUQ UERQ UE, Luís. Paraa História da Ciência em Portugal. Lisboa: Livros Horizonte, 1973

ARAÚJO, Helena Costa. Precocidade e «Retórica»na construção da escola de massas em Portugal. Educação, Sociedade e Culturas, n. 5, 1996.

CORVO, João Andrade; A instrução pública. (discurso pronunciado nas sessões de 9, 10 e 11 Abril de 1866), Lisboa: Imprensa nacional, 1866.

DUBY, Georges; PERROT, Michelle; História das mulheres: do Renascimento à Idade Moderna. Lisboa:Afrontamento. 1994. v. 3.

ESTATUTOS da Universidade de Coimbra. 2. ed. Coimbra: Universidade de Coimbra, 1972. v. 3.

FREIRE, F. C. Memoria da faculdade de mathematica. Coimbra: Imprensa da Universidade de Coimbra, 1872.

HENRIQUES, H. A. C. O percurso da matemática no ensino técnico durante a monarquia. 2004. Tese (Doutoramento) - Universidade Portucalense Infante D. Henrique, Porto, 2004. 
SANTOS, Cândido dos. Universidade do Porto: raízes e memórias da instituição. Porto: Reitoria da Universidade do Porto. 1996.

PARDAL, Luís; VENTURA, Alexandre; Dias, Carlos. O ensino técnico em Portugal. Universidade de Aveiro. 2003

PINTO, Teresa. 0 ensino industrial feminino oitocentista. A Escola Damião de Góis em Alenquer. Lisboa: Colibri, 2000.

ROUSSEAU, Jean-Jacques. Émile ou De l'éducacion. NRF, Bibliothéque de la Pléiade. [S.l.:s.n. , [19-?] Livro V

Recebido: 26 de janeiro de 2006 Aprovado: 28 de março de 2006. 